\title{
National and regional asthma programmes in Europe
}

\author{
Olof Selroos ${ }^{1}$, Maciej Kupczyk ${ }^{2}$, Piotr Kuna ${ }^{2}$, Piotr Łacwik ${ }^{2}$, Jean Bousquet ${ }^{3}$, \\ David Brennan ${ }^{4}$, Susanna Palkonen ${ }^{4}$, Javier Contreras ${ }^{5}$, Mark FitzGerald ${ }^{6}$, \\ Gunilla Hedlin ${ }^{7}$, Sebastian L. Johnston ${ }^{8}$, Renaud Louis ${ }^{9}$, Leanne Metcalf ${ }^{10}$, \\ Samantha Walker ${ }^{10}$, Antonio Moreno-Galdó ${ }^{11}$, Nikolaos G. Papadopoulos ${ }^{12}$, \\ José Rosado-Pinto ${ }^{13}$, Pippa Powell ${ }^{14}$ and Tari Haahtela ${ }^{15}$
}

Affiliations: 'Selroos Medical Consulting (Semeco AB), Ängelholm, Sweden. ${ }^{2}$ Dept of Internal Medicine, Asthma and Allergy, Barlicki University Hospital, Medical University of Lodz, Lodz, Poland. ${ }^{3}$ National Institute for Health and Medical Research (INSERM), Paris, France. ${ }^{4}$ European Federation of Asthma and Airways Diseases Patients' Association (EFA), Brussels, Belgium. ${ }^{5}$ National Federation of Respiratory Disease Associations (FENAER), Malaga, Spain. ${ }^{6}$ Institute for Heart and Lung Health, Vancouver, Canada. ${ }^{7}$ Centre for Allergy Research, Karolinska Institutet, Stockholm, Sweden. ${ }^{8}$ Airway Disease Infection Section, National Heart and Lung Institute, Imperial College, London, UK. ${ }^{9}$ Dept of Pneumology, CHU Sart-Tilman Liège, Liège, Belgium. ${ }^{10}$ Asthma UK, London, UK. ${ }^{11}$ Pediatric Pulmonology Unit, Hospital Vall d'Hebron, Barcelona, Spain. ${ }^{12}$ Dept of Allergology, University of Athens, Athens, Greece. ${ }^{13}$ Immunoallergology Dept, Hospital da Luz, Lisbon, Portugal. ${ }^{14}$ European Lung Foundation, Sheffield, UK. ${ }^{15}$ Skin and Allergy Hospital, Helsinki University Central Hospital, Helsinki, Finland.

Correspondence: Olof Selroos, Selroos Medical Consulting (Semeco AB), Skogsvägen 5, Vejbystrand, SE-266 54, Sweden. E-mail: olof.selroosatelia.com

ABSTRACT This review presents seven national asthma programmes to support the European Asthma Research and Innovation Partnership in developing strategies to reduce asthma mortality and morbidity across Europe. From published data it appears that in order to influence asthma care, national/regional asthma programmes are more effective than conventional treatment guidelines. An asthma programme should start with the universal commitments of stakeholders at all levels and the programme has to be endorsed by political and governmental bodies. When the national problems have been identified, the goals of the programme have to be clearly defined with measures to evaluate progress. An action plan has to be developed, including defined re-allocation of patients and existing resources, if necessary, between primary care and specialised healthcare units or hospital centres. Patients should be involved in guided self-management education and structured follow-up in relation to disease severity. The three evaluated programmes show that, thanks to rigorous efforts, it is possible to improve patients' quality of life and reduce hospitalisation, asthma mortality, sick leave and disability pensions. The direct and indirect costs, both for the individual patient and for society, can be significantly reduced. The results can form the basis for development of further programme activities in Europe.

@ERSpublications

Current asthma programmes confirm patients' quality of life can be improved while significantly reducing costs http://ow.ly/Q8dR0

This article has supplementary material available from err.ersjournals.com

Received: Sept 022014 | Accepted after revision: Oct 162014

Support statement: The European Asthma Research and Innovation Partnership is funded by the European Union 7th Framework programme (grant agreement 602077).

Conflict of interest: P. Powell is an employee of the European Lung Foundation. Other disclosures can be found alongside the online version of this article at err.ersjournals.com

Provenance: Submitted article, peer reviewed.

Copyright OERS 2015. ERR articles are open access and distributed under the terms of the Creative Commons Attribution Non-Commercial Licence 4.0. 


\section{Introduction}

In Europe, almost 10 million people $<45$ years of age have asthma [1]. The prevalence of asthma in the European Union (EU) is $8.2 \%$ in adults and $9.4 \%$ in children.

In 2013, the World Health Organization (WHO) estimated that every year 25 billion disability-adjusted life years (DALYs) are lost because of asthma [2]; of this, 5.2 billion DALYs are lost within the EU [1]. Asthma is the most common noncommunicable disease among children [3]. In the majority of cases asthma is mild, but severe asthma occurs in $10-20 \%$ of patients [4]. The direct and indirect costs of asthma to societies are substantial [5]. Recent calculations estimate direct costs within the EU to be nearly $€ 20$ billion, indirect costs to be $€ 14$ billion and a monetised value of DALYs lost to be $€ 38$ billion, which totals $€ 72$ billion [6].

Together, the increasing prevalence of asthma, its costly burdens on European societies and the persistent gaps in asthma research have provided the rationale for the European Asthma Research and Innovation Partnership (EARIP). EARIP, supported by the 7th Framework Programme of the European Commission, has been prioritised by the EU to unite Europe with a common asthma research agenda for the next decade. Additionally, it aims to build on and harmonise existing individual asthma activities, in order to generate interconnectivity in asthma management and develop a comprehensive and focused approach to reduce asthma-related mortality and morbidity across Europe, catalysing societal gains by directly linking research to public breakthroughs. The present overview of European national asthma programmes ensures that EARIP identifies current best practices and integrates them into new recommendations for research and innovation needs. It will be of key importance for EARIP's discussions of health and care system change to help identify processes that have truly improved outcomes and been effective at keeping patients at the centre of asthma management and treatment. Promotion of such practices can help EARIP to cut asthma deaths in Europe, reduce hospitalisations and increase optimal self-management.

In Finland between 1994 and 2004, a structured national asthma programme resulted in significant reductions in asthma morbidity, hospital admissions, disability pensions and costs [7, 8]. This was achieved with: earlier diagnosis and active treatment (inhaled corticosteroids as first-line therapy); implementation of simple guidelines; organisation of collaboration between primary care and specialists; development of local asthma physician, nurse and pharmacist networks; and patient-centred asthma education and empowerment (guided self-management).

National asthma programmes somewhat analogous to the Finnish one have been initiated in other European countries, including: France [9], Ireland [10, 11], Italy [12], the Netherlands [13], Poland [1416], Portugal [17, 18] and Turkey [19-24]. The Norwegian government issued a national asthma programme in 2008-2012, but it is only available in the local language [25]. Additional programmes in other local languages probably exist although they are not internationally recognised. A nationwide registry for severe asthma was established in Belgium in 2009 [26].

Successful results of national asthma programmes outside Europe have been reported from Australia [27, 28], Canada [29, 30], Singapore [31], Brazil [32], Costa Rica [33] and Tonga [34].

Asthma guidelines are valuable but useless if they are poorly implemented and too complex for adoption by primary care physicians [35-38]. The Global Initiative for Asthma (GINA) has clearly seen implementation as the most urgent priority if progress is to be made in addressing asthma care through guidelines [38]. Initiatives aiming to improve asthma care need to be well-planned and coordinated. It is an advantage if they are initiated or supported by governmental bodies [39, 40]. The positive results of published coordinated activities, such as in Finland, together with the increased burden of the disease, have called for integral involvement of policymakers and healthcare officials [41, 42].

The Global Asthma Network (GAN) is an organisation that includes asthma centres in more than 100 countries (28 in Europe) (www.globalasthmanetwork.org). GAN follows up the achievements of the International Studies on Asthma and Allergy in Childhood (ISAAC) programme 1991-2012 [43-46]. In 2011, GAN reported that $>60 \%$ of the participating countries had their own asthma guidelines for adults and children. In addition, international guidelines for adult and childhood asthma were used in $10 \%$ and $12 \%$ of the countries, respectively.

The results of clinical surveys, such as the GAN 2011 report [47], have resulted in important initiatives at the political level. In 2011, the European Council recognised asthma as the most common, chronic noncommunicable disease of childhood. The council recommended its member states to initiate programmes with integrated prevention, early diagnosis and treatment, through cooperation with relevant stakeholders, especially patient and health professional organisations [48, 49]. "A community problem needs community solutions" [7]: all healthcare professionals should collaborate and agree about the structural changes necessary to improve management. 


\section{Definitions}

Asthma programme

A well-described activity planned to influence a defined burden of asthma within a nation or region, with defined time lines and goals and with a structured implementation plan to achieve the goals. A programme also includes the description of necessary resources and their possible re-allocation, and a defined follow-up plan and presentation of results.

\section{Asthma guideline}

A document developed by international or national/regional experts in order to best describe optimal management and treatment of asthma.

\section{Asthma action plan}

A description of how an individual patient should manage asthma, including advice for changes in medication, if necessary, and a plan for contact with the healthcare system.

\section{Aims}

The activities of EARIP aim to reduce asthma mortality in Europe by $25 \%$ within 10 years and by $50 \%$ within 20 years. The partnership, made up of 12 European-based organisations, also aims to halve hospital admissions rates, speed up the discovery of new treatments and improve self-management. In order to form an updated platform for achieving the goals, the European Federation of Allergy and Airways Diseases Patients' Association (EFA), within the framework of the EARIP project, initiated a systematic review of European national and regional asthma programmes.

To achieve these goals, one starting point is to identify the steps and procedures within those published programmes that have resulted in measurable effects. Thereby key requirements are identified for replication programmes in different national contexts.

\section{Methods}

We identified publications on national and regional initiatives that aimed to improve quality of asthma care in a large population. Articles were selected when they presented clear goals and measurable results of such interventions.

The terminology related to asthma programmes, plans, guidelines and strategies is confusing [50]. In this review, we define an asthma programme as an activity with: defined time frames; identified management and treatment problems; clear goals for planned activities; definition and implementation of strategies to achieve the goals; and results of the interventions.

A systematic search was conducted in PubMed, the Cochrane Database of Systemic Reviews, EMBASE, Web of Science and the Science Citation Index using the following specific keywords: "asthma plan"; "national asthma plan"; "asthma programme"; "asthma program"; "national asthma programme"; "national asthma program"; "asthma health care plan"; "POLASTMA"; "Programme for Control of Asthma and Allergic Rhinitis (ProAR)"; "Finnish asthma programme"; "asthma health promotion"; "asthma education"; "asthma cost effectiveness"; "national asthma agenda"; "national asthma project"; "national asthma strategy"; and "national asthma policy".

A total of 12531 citations were screened based on the title and topic; 732 potentially relevant articles were identified for further evaluation. The excluded group consisted mostly of publications on individual patient asthma plans, comparisons of different treatment strategies, genetic studies, research programmes with no intervention component and programmes conducted on small groups of people. After processing the initial results and excluding all duplicates, the remaining 412 article abstracts were evaluated for inclusion, obtaining the full text where necessary. Finally, 147 articles were chosen that we found relevant for review. Out of these, a total of 53 publications referred to national asthma programmes and 19 were European, of which eight specifically referred to the national asthma programme in Finland. There were 68 regional programmes, mostly from the USA, and only two from Europe. In addition, other national programmes were identified via the Global Alliance against Chronic Respiratory Diseases (GARD) documents, reference lists of published papers and press releases. The Asthma Health Outcomes Project (AHOP) in the USA was also reviewed as it had identified 532 activities related to asthma in 30 countries and 46 US states, including qualitative data from 223 so-called asthma programmes [51].

\section{Results}

Identified national asthma programmes in Europe are listed in table 1. More details about the programmes and their results are summarised in the tables E1 and E2. The first European National Asthma Programme 
TABLE 1 National and regional asthma programmes identified in Europe

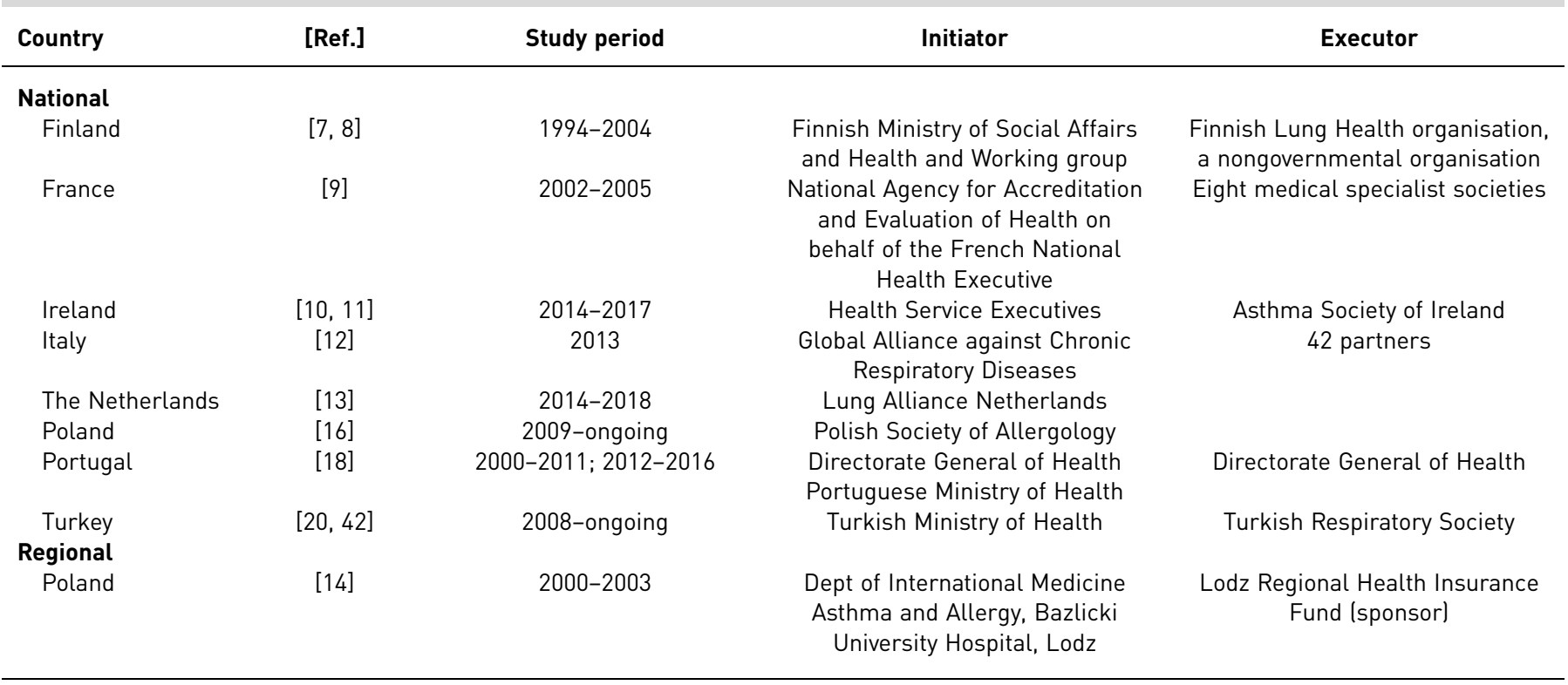

was the Finnish 10-year programme (1994-2004), which has been the model for other European and non-European programmes. Results and several follow-up reports of the Finnish programme have been published previously [52-59]. Apart from the Finnish programme, results have only been published from the Polish [14, 15] and Portuguese [17] programmes. The other listed programmes have started recently and results are not yet available.

\section{Finnish programme}

The programme in Finland began because the prevalence of asthma and societal burden of the disease was increasing in the 1980s and 1990s. Asthma was the third most common chronic disorder requiring long-term medication after hypertension and coronary heart disease. The number of new cases, calculated from the number of patients entitled to special reimbursement for prescriptions of anti-asthma drugs, increased from 1986 to 1995, and increased most rapidly among children and adolescents. In 1995, approximately 150000 patients (table E1), $3 \%$ of the population, received special drug reimbursement based on physician-diagnosed asthma and the need for regular maintenance medication. The majority of the patients (60\%) suffered from mild asthma, 20\% from moderate asthma and $20 \%$ from severe asthma [39]. In the early 1990s, the overall annual costs of asthma were estimated at US $\$ 600$ billion. This included direct costs for medical care and indirect costs related to disabilities and loss of production. The costs of severe asthma accounted for $\sim 60 \%$ of the total costs. The main achievements of the Finnish Asthma programme are shown in the tables E1 and E2, and these align closely with the ambitions for EARIP.

During the programme period there was a continuous growth in the number of asthma patients entitled to special reimbursement for their drug costs (mainly due to increase of patients receiving proper treatment) (fig. 1). Simultaneously, the burden of asthma started to decrease, e.g. the number of asthma-related hospital days fell by $54 \%$.

Since the end of the programme in 2004, the positive development has continued. A 24-year follow-up demonstrated that the number of patients with persistent asthma in the national health insurance registry tripled [56] (unpublished observation). In these people, asthma control was improved and, disability pensions and sickness allowances decreased further. The total annual asthma-related costs fell by $32 \%$, from $€ 287$ billion to $€ 196$ billion. The major cost saver was a decrease in indirect costs driven by disability pensions. However, annual direct healthcare costs increased by $28 \%$, from $€ 82$ billion to $€ 105$ billion due to increased use of drugs. Overall, annual costs per patient decreased by $75 \%$, a fall from $€ 3452$ to $€ 834$. The annual theoretical total cost savings during the year 2010, compared to predicted, were at least $€ 300$ billion.

In a follow-up study of the Finnish programme from 2000 to 2010, although the total number of hospital days continued to fall, a relative increase was found in patients aged $>65$ years, and particularly in females [58]. 


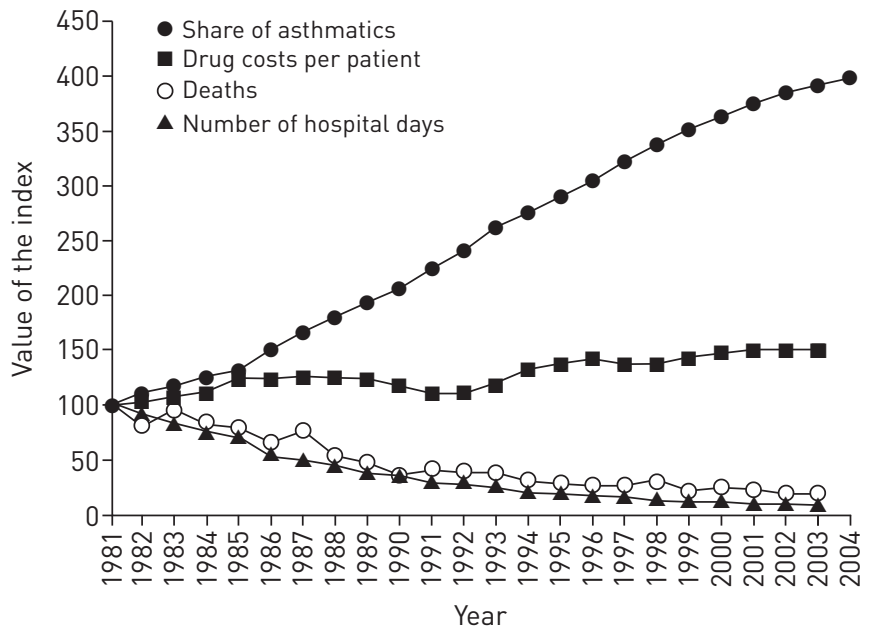

FIGURE 1 Increase in number of asthmatic patients entitled to special reimbursement for their drug costs (need for regular maintenance treatment), increase in drug costs per patient, decrease in death rate and decrease in hospital days due to asthma. Numbers are relative changes after 1981. Reproduced from [8].

Results from the follow-up study showed costs for asthma totalling $€ 206$ billion, the majority of which was made up of the cost of drugs ( $€ 108$ billion) and primary care visits ( $€ 63$ billion). The changes during the period 2000-2011 were a reduction in costs of visits to the doctor ( $€ 59-€ 43$ billion), rehabilitation ( $€ 5-$ $€ 2$ billion) and disability pensions (€60-€22 billion) [55]. The real costs in relation to expected costs if no programme had been implemented are presented in figure 2.

A recent study performed in Finnish pharmacies showed that a change in asthma severity has occurred in the country as the number of severe asthmatics has dropped from $10 \%$ (in 2000) to $4 \%$ (in 2010) [60]. In 1987, only one-third of all patients with asthma used controller medication [8], but in $200485 \%$ of the patients already used inhaled corticosteroids on a daily basis [58]. This change in use of controller medication implies better asthma control at a population level.

\section{Achievements in other countries}

The results of the regional programme in 2000-2003 in the Lodz area of Poland also showed a decrease in hospital days, length of hospitalisation and overall asthma costs despite an increase in number of patients (table E2) [14, 15]. The Portuguese national programme in 2000-2007 showed a $15 \%$ reduction in hospitalisation rate (table E2) [17].

In Spain, several regional programmes have been initiated since 1992. In northwest Spain, hospital admissions due to childhood asthma decreased from 2.91 per 1000 inhabitants in 1995 to 1.33 per 1000 inhabitants in 2007 [61]. In France admissions decreased from 10.8 per 10000 inhabitants in 1998 to 8.6 per 10000 inhabitants in 2002 in patients aged $\geqslant 10$ years [62]. The admission rate has further decreased since the implementation of the National Asthma Programme (fig. 3).

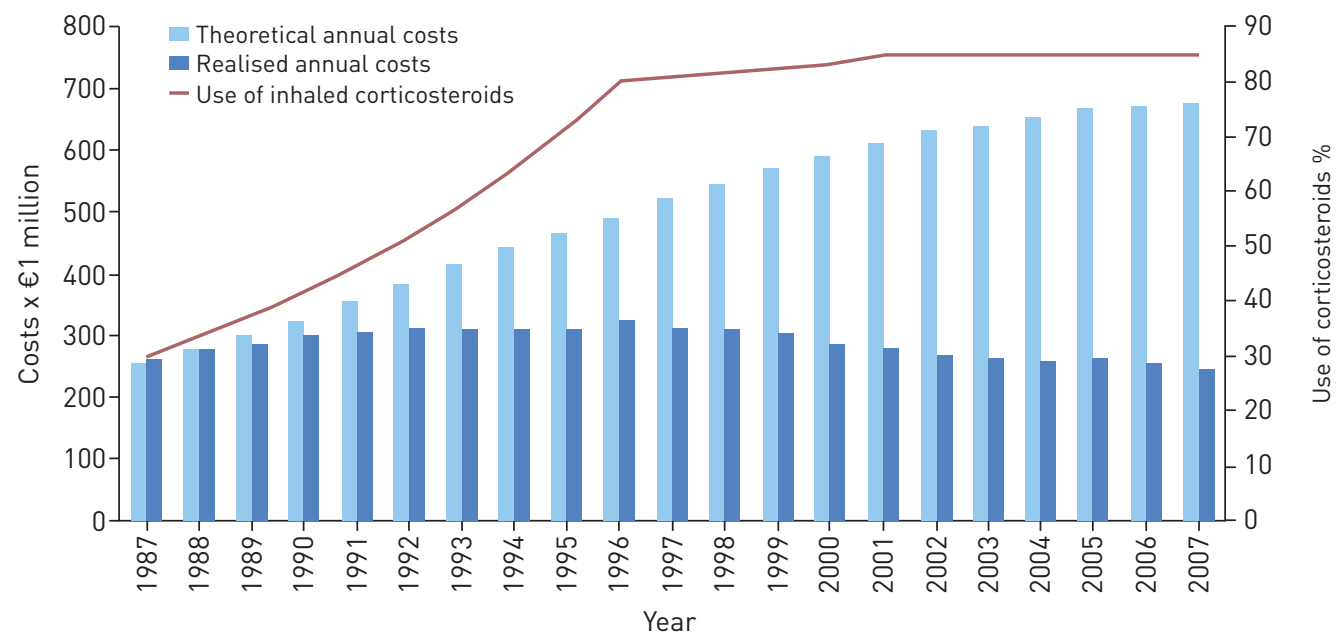

FIGURE 2 Realised annual expenditures of asthma care and theoretical annual costs where an increased prevalence of asthma is observed, but care practices remain at the 1987 level. Reproduced and modified from [55] with permission from the publisher. 
FIGURE 3 Hospital admission rates in France during implementation of the National Asthma Programme. Data from the Agence Technique de l'Information sur l'Hospitalisation.

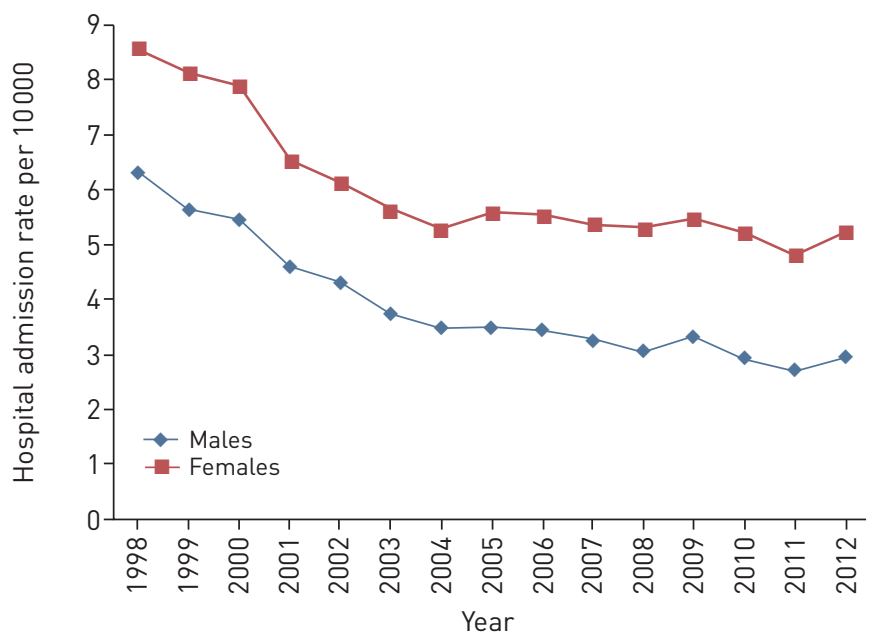

During the past two decades (1990-2008), the prevalence of asthma-related symptoms in the Swedish population aged 20-44 years has remained unchanged at 7\% [63]. In Sweden, Denmark and Norway, national asthma treatment guidelines have been published [64-66] and implemented; in particular, the early use of inhaled corticosteroids has been widely accepted. A recent random population survey reported the use of asthma drugs in Sweden in 2010 compared with 1992 [67]. A five-fold increase in the use of inhaled corticosteroids was noted since 1990 , from $1.5 \%$ to $7.7 \%$ of the population, and a decrease in the use of short-acting $\beta_{2}$-agonists was reported. As mentioned previously, this change in use of asthma medication may imply better asthma control and corroborates the increase in use of inhaled corticosteroids in Finland $[7,8]$. In a multinational study based on the European Community Respiratory Health Survey series of patients (including 12 European countries), a positive change in asthma-related outcomes was noticed in parallel with an increase in the use of inhaled corticosteroids [68]. Asthma-related mortality in Europe has also significantly decreased, from 6287 deaths in 1985 to 1164 in 2012 (-80\%) [69]. This shows that good results can also be achieved without formal national asthma programmes, as long as evidence-based guidelines are implemented and widely used.

\section{Discussion}

In many countries and regions, physicians and professional organisations devoted to the care of patients with asthma have adopted international asthma guidelines and developed regional or local versions and clinical routines. These activities have been associated with improvements in the management and control of individual patients' asthma [70,71]. At the same time, the importance of patient involvement in their treatment has become evident as strategies for guided self-management have been developed and gradually improved. In the mid-1990s, early randomised studies showed that guided self-management with patients' own adjustment of anti-inflammatory medication based on symptoms and home peak flow measurements reduced exacerbations and other asthma events compared with traditional therapy [72]. This also resulted in reduced asthma care costs [73]. A systematic review of 36 trials found guided self-management of asthma in adults to be clearly advantageous compared with usual care and to significantly improve patients' health [74].

This systematic review of national and/or regional asthma programmes within Europe shows that during recent years several important initiatives have been undertaken. Several activities have been started within the GARD programme, together with activities against other chronic respiratory diseases [41, 42]. The management and treatment recommendations have been based on international asthma guidelines [4].

However, so far, only a few results based on programme experiences have been published. Only results from a regional programme in Poland [14, 15], and national programmes in Portugal [17] and Turkey [42] have been published in addition to the 17-year results of the Finnish programme [58]. An achievement with all programmes has been a clear reduction in asthma-caused hospitalisation rates. However, small steps towards improved asthma care have also been taken in other European countries. In Romania, "World day of COPD" in 2010-2012, including asthma, resulted in a three-fold increase in the number of new cases with a diagnosis of asthma [75]. In the Czech Republic, GARD leaders launched CARO (Czech Alliance against Chronic Respiratory Diseases) in 2007. In collaboration with 21 other stakeholders (national scientific, academic, professional and patients' organisations), they have planned coordinated activities against chronic respiratory diseases, including asthma [42]. Over the past 2 years, national programmes have also been initiated in Ireland [11], Italy [12] and the Netherlands [42]. 
In order to better understand what makes asthma programmes successful, AHOP gives some important information [51]. A total of 427 national and international activities were reviewed and a range of factors were identified that were associated with positive outcomes. The observations suggested that the first decision of programme implementers should be to determine the outcome(s) on which they wish to have an impact. If the goal is to reduce healthcare use, then data suggested that attention should be paid to its relationships with clinical care providers, community-based organisations and relevant governmental bodies. If the goal is to improve medication use, collaboration is especially important because it is likely to enhance access to and appreciation of asthma therapies [51]. The key issues associated with successful programmes were community centeredness, clinical connectivity, collaboration and responsiveness to needs.

National asthma programmes should be built on evidence-based guidelines developed by expert organisations, with input from primary care and patient groups. However, if guidelines are too detailed and complicated, they may be poorly implemented. There are several barriers to overcome in order for guidelines to be used in every day clinical practice. The problems may not only be in the content of guidelines, but also the to local behaviour and habits of physicians and patients [36-38]. Even the best guidelines are useless if they are not widely and successfully promoted and implemented [76].

The lessons to be learnt from national asthma programmes are also presented in figure 4. Programme development should be based on evidence and practical knowledge. The planning and implementation of the programme needs broad commitments from healthcare professionals and governmental bodies and other stakeholders. The working group/society developing the programme development must realise that a prospective action plan is required. Depending on the situation in the country/region, the goals, which are preferably quantitative, can be divided into several steps, but every goal has to be well defined. The follow-up activities, including presentation of results, should also be expressly outlined at the outset. Official registers should be effectively developed and employed.

This review has shown that successful asthma programmes have the following clinical characteristics: 1) improving early diagnosis and introduction of first-line treatment with anti-inflammatory medication (mainly inhaled corticosteroids); 2) improving long-term disease control; 3) introducing simple means for guided self-management to proactively prevent exacerbations or attacks; and 4) effective education and networking with general practitioners, nurses and pharmacists. A systematic approach is needed with emphasis placed on motivation and organisation. Improvements can be achieved by relatively simple

Background

\begin{tabular}{|l|l|l|}
\hline $\begin{array}{l}\text { New body of } \\
\text { knowledge } \\
\text { Disability caused by } \\
\text { asthma can be } \\
\text { prevented }\end{array}$ & $\begin{array}{l}\text { Conclusions } \\
\text { Epidemiology } \\
\text { Morbidity } \\
\text { Prevalence }\end{array}$ \\
$\begin{array}{l}\text { Economy } \\
\text { Costa }\end{array}$ \\
$\begin{array}{l}\text { Evidence } \\
\text { - Implementalth } \\
\text { best practices is } \\
\text { highly cost-effective } \\
\text { both on the patient } \\
\text { and societal levels } \\
\text { consensus } \\
\text { - Need for action } \\
\text { - Identification of } \\
\text { key stakeholders } \\
\text { - Focus on patients } \\
\text { - Focus on severe } \\
\text { asthma to stop } \\
\text { exacerbations/ } \\
\text { attacks } \\
\text { Focus on effective } \\
\text { use of available } \\
\text { resources and } \\
\text { registers }\end{array}$ \\
\hline
\end{tabular}

4-step action plan

\begin{tabular}{|c|c|c|}
\hline $\begin{array}{l}\text { - Strategic choices } \\
\text { - Practical action plan, not a } \\
\text { consensus report } \\
\text { - Strategies for: 1) the } \\
\text { diseased, and 2) the } \\
\text { general population } \\
\text { - Quantitative and qualitative } \\
\text { goals } \\
\text { - Focus on primary } \\
\text { healthcare and outpatient } \\
\text { services } \\
\text { - Promotion of asthma health } \\
\text { - Asthma control tools for } \\
\text { guided self-management } \\
\text { to stop exacerbations/ } \\
\text { attacks } \\
\text { - Search for critical mass for } \\
\text { change through education } \\
\text { and counselling }\end{array}$ & $\begin{array}{l}\text { Goals, } \\
\text { measures } \\
\text { - 1-3 key } \\
\text { messages for } \\
\text { the public } \\
\text { - } 3-5 \text { numerical } \\
\text { goals for } \\
\text { healthcare to } \\
\text { reduce the } \\
\text { burden } \\
\text { - Tools to be } \\
\text { used locally } \\
\text { - Measures to } \\
\text { follow } \\
\text { outcomes } \\
\text { - Timelines }\end{array}$ & $\begin{array}{l}\text { Activities } \\
\text { - Leadership, steering } \\
\text { group (local, national) } \\
\text { - Capacity building, } \\
\text { funding } \\
\text { - New internet-based } \\
\text { networking with } \\
\text { specialists, GPs, nurses } \\
\text { and pharmacists } \\
\text { - In diagnostic work, } \\
\text { improving early } \\
\text { detection } \\
\text { - In treatment, improving } \\
\text { effective use of ICS } \\
\text { - Education and publicity } \\
\text { (with NGOs) } \\
\text { - Legislation (essential } \\
\text { medication, } \\
\text { anti-smoking) } \\
\text { - Feedback, follow-up }\end{array}$ \\
\hline
\end{tabular}

FIGURE 4 Flow chart of strategic planning, implementation and evaluation of the programme. GP: general practitioner; ICS: inhaled corticosteroid; NGO: non-governmental organisation. Reproduced and modified from [7] with permission from the publisher. 
means. All the main stakeholders should be represented when multidisciplinary actions are planned. The involvement of nongovernmental organisations and patient organisations is especially important, as these groups are aware of the grass-root problems and enable patient and family commitment. Any programme should set three to five goals, preferably numerical, and for each goal, specific targets (what to do), tools (how to do it) and outcomes (what to follow and measure) should be defined.

All the experience from the national and local interventions converges, regardless of the healthcare system and its coverage. A major change for the better can be achieved by local efforts, systematic planning and networking to implement best asthma practices. The gain is remarkable, both in reducing human suffering as well as societal costs. The asthma burden can be tackled, and it is the responsibility of asthma experts and healthcare professionals to collaborate with national public health authorities, patient organisations and international organisations for better efficiency, management and care.

There is a bias with this review. The search was restricted to published data and many national programmes were probably not found. There is also a number of limitations when interpreting the results of the published asthma programmes. First, there are few little data to compare the interventions in different countries or areas. Because real-life large populations are included, no control groups exist. Comparable data is also lacking in terms of planning, organisation and implementation activities. It must be recognised that efforts and time given to the programmes, and the willingness within the healthcare system to accept proposed changes, have had an impact on their success (e.g. the Finnish programme). Secondly, when programmes are running for a long period of time, it cannot be ignored that changes have occurred in management principles for other reasons apart from the programme. Maybe the physicians' behaviour has changed in terms of criteria for inpatient admission. The possibility to hospitalise a patient may also be influenced by administrative changes in the healthcare system resulting in reduced availability of hospital beds. The overall picture of asthma may also change as more patients with mild disease have been diagnosed and this will be reflected in the calculations of costs per patient.

Nevertheless, this review shows that clear improvements have been seen in asthma care in countries where asthma programmes have been initiated. It is also obvious that asthma mortality has declined although it cannot be claimed that the main reason behind this change would be the access to specific asthma programmes. The awareness of asthma guidelines has certainly also played a role, as shown by the Scandinavian experiences [63,67]. Despite all these limitations, the present review can contribute to rational initiatives and activities as planned within EARIP.

\section{Acknowledgements}

The European Asthma Research and Innovation Partnership consortium partners and coauthors also acknowledge the contributions of Anne Elisabeth Eriksrud (Norwegian Asthma and Allergy Federation, Oslo, Norway) and Ilkka Repo (Finnish Asthma and Allergy Federation, Helsinki, Finland).

\section{References}

1 Gibson J, Loddenkemper R, Sibille Y, et al., eds. The European Lung White Book. Respiratory Health and Disease in Europe. Sheffield, European Respiratory Society, 2013.

2 World Health Organization. Chronic respiratory diseases. Asthma. www.who.int/respiratory/asthma Date last updated: 2013. Date last accessed: February 21, 2014.

3 van den Akker-van Marle ME, Bruil J, Detmar SB. Evaluation of cost of disease: assessing the burden to society of asthma in children in the European Union. Allergy 2005; 60: 140-149.

4 Global Initiative for Asthma. Global Strategy for Asthma Management and Prevention. www.ginasthma.org/local/ uploads/files/GINA_Report_2014_Aug12.pdf Date last updated: 2014. Date last accessed: April 20, 2014.

5 Bahadori K, Doyle-Waters MM, Marra C, et al. Economic burden of asthma: a systematic review. BMC Pulm Med 2009; 9: 24.

6 Gibson J, Loddenkemper R, Sibille Y, et al., eds. Lung Health in Europe. Facts and Figures. Sheffield, European Respiratory Society/European Lung Foundation, 2013.

7 Haahtela T, Klaukka T, Koskela K, et al. Asthma programme in Finland: a community problem needs community solutions. Thorax 2001; 56: 806-814.

8 Haahtela T, Tuomisto LE, Pietinalho A, et al. A 10 year asthma programme in Finland: major change for the better. Thorax 2006; 61: 663-670.

9 Mortensen J, Renda A. Asthma in the EU. Towards better management and regulation of a public health issue. Brussels, Centre for European Policy Studies, 2007.

10 Manning P, Greally P, Shanahan E. Asthma control and management: a patient's perspective. Ir Med J 2005; 98 : 231-232.

11 Asthma Society of Ireland. Time to take action on asthma in Ireland. www.asthma.ie/news/time-take-actionasthma-ireland. Date last updated: May 6, 2015. Date last accessed: June 8, 2015.

12 Laurendi G, Mele S, Centanni S, et al. Global alliance against chronic respiratory diseases in Italy (GARD-Italy): strategy and activities. Respir Med 2012; 106: 1-8.

13 World Health Organization. Global Alliance Against Chronic Respiratory Diseases (GARD). Report from the 8th general meeting. Chapter 4.2 The Netherlands. WHO/NMH/MND/CPM/13.3. Geneva, WHO, 2013.

14 Stelmach W, Majak P, Jerzynska J, et al. Early effects of asthma prevention program on asthma diagnosis and hospitalization in urban population of Poland. Allergy 2005; 60: 606-610. 
15 Kupczyk M, Haahtela T, Cruz AA, et al. Reduction of asthma burden is possible through national asthma plans. Allergy 2010; 65: 415-419.

16 Kuna P, Kupczyk M, Kupryś-Lipińska I. POLASTMA - the Polish National Programme of Early Diagnostics and Treatment of Asthma. Pneumonol Alergol Pol 2014; 82: 597-607.

17 Bugalho de Almeida A, Covas A, Prates L, et al. Asthma hospital admission and mortality in mainland Portugal 2000-2007. Rev Portuguesa Pneumol 2009; 15: 367-383.

18 Fonseca Antunes A, Bárbara C, Melo Gomes E. Portuguese National Programme for Respiratory Diseases 2012/ 2016. Lisbon, DGS, 2012.

19 Lalloo UG, Walters RD, Adachi M, et al. Asthma programmes in diverse regions of the world: challenges, successes and lessons learnt. Int J Tuberc Lung Dis 2011; 15: 1574-1587.

20 Yorgancioğlu A, Yardim N, Ergün P, et al. Integration of GARD Turkey national programme with other non-communicable diseases plans in Turkey. Tüberküloz ve Toraks Dergisi 2010; 58: 213-228.

21 Sekerel BE, Saraclar Y, Ones U, et al. Childhood asthma perception in Turkey under real-life environment (CAPTURE) study. Pediatr Allergy Immunol 2001; 12: 266-273.

22 Beyhun NE, Soyer OU, Kuyucu S, et al. A multi-center survey of childhood asthma in Turkey - I: the cost and its determinants. Pediatr Allergy Immunol 2009; 20: 72-80.

23 Soyer OU, Beyhun NE, Demir E, et al. A multicenter survey of childhood asthma in Turkey. II: utilization of asthma drugs, control levels and their determinants. Pediatr Allergy Immunol 2009; 20: 172-179.

24 Turktas H, Mungan D, Uysal MA, et al. Determinants of asthma control in tertiary level in Turkey: a cross-sectional multicenter survey. J Asthma 2010; 47: 557-562.

25 Helse- og Omsorgsdepartementet. National strategy for prevention and treatment of asthma and allergy diseases 2008-2012 (in Norwegian). www.regjeringen.no/nb/tema/helse-og-omsorg/folkehelse/nasjonal-strategi-forforebygging-og-beh/id510004/

26 Schleich F, Brusselle G, Louis R, et al. Heterogeneity of phenotypes in severe asthmatics. The Belgian severe asthma registry (BSAR). Respir Med 2014; 108: 1723-1732.

27 National Asthma Council Australia. Australian Asthma Handbook. www.nationalasthma.org.au/handbook. Date last updated: April 2015. Date last accessed: June 9, 2015.

28 McCaul KA, Wakefield MA, Roder DM, et al. Trends in hospital readmission for asthma: has the Australian National Asthma Campaign had an effect? Med J Austr 2000; 172: 62-66.

29 Boulet LP, Dorval E, Labrecque M, et al. Towards excellence in asthma management: final report of an eight-year program aimed at reducing care gaps in asthma management in Quebec. Can Respir J 2008; 15: 302-310.

30 To T, Cicutto L, Degani N, et al. Can a community evidence-based asthma care program improve clinical outcomes? A longitudinal study. Med Care 2008; 46: 1257-1266.

31 Chong PN, Tan NC, Lim TK. Impact of the Singapore national asthma program (SNAP) on preventor-reliever prescription ratio in polyclinics. Ann Acad Med Singapore 2008; 37: 114-117.

32 Cruz AA, Souza-Machado A, Franco R, et al. The impact of a program for control of asthma in a low-income setting. World Allergy Organ J 2010; 3: 167-174.

33 Soto-Martínez M, Avila L, Soto N, et al. Trends in hospitalizations and mortality from asthma in Costa Rica over a 12- to 15-year period. J Allergy Clin Immunol Pract 2014; 2: 85-90.

34 Foliaki S, Fakakovikaetau T, D'Souza W, et al. Reduction in asthma morbidity following a community-based asthma self-management programme in Tonga. Int J Tuberc Lung Dis 2009; 13: 142-147.

35 Partridge MR. Translating research into practice: how are guidelines implemented? Eur Respir J 2003; 21: Suppl. $39,23 s-29 s$.

36 Harrison MB, Légaré F, Graham ID, et al. Adapting clinical practice guidelines to local context and assessing barriers to their use. CMAJ 2010; 182: E78-E84.

37 Baiardini I, Braido F, Bonini M, et al. Why do doctors and patients not follow guidelines? Curr Opin Allergy Clin Immunol 2009; 9: 228-233.

38 Boulet LP, FitzGerald JM, Levy ML, et al. A guide to the translation of the Global Initiative for Asthma (GINA) strategy into improved care. Eur Respir J 2012; 39: 1220-1229.

39 Haahtela T, Laitinen LA, Koskela K, et al. Asthma programme in Finland 1994-2004. Report of a working group. Clin Exp Allergy 1996; 26: 1-24.

40 Haahtela T, von Hertzen L, Mäkelä M, et al. Finnish Allergy Programme 2008-2018 - time to act and change the course. Allergy 2008; 63: 634-645.

41 Bousquet J, Dahl R, Khaltaev N. Global Alliance against Chronic Respiratory Diseases. Eur Respir J 2007; 29: 233-239.

42 Yorgancioğlu A, Cruz AA, Bousquet J, et al. The Global Alliance against Respiratory Diseases (GARD) country report. Prim Care Respir J 2014; 23: 98-101.

43 Asher MI, Montefort S, Björkstén B, et al. Worldwide time trends in the prevalence of symptoms of asthma, allergic rhinoconjunctivitis, and eczema in childhood: ISAAC phases one and three repeat multicountry cross-sectional surveys. Lancet 2006; 368: 733-743.

44 Pearce N, Air-Khaled N, Beasley R, et al. Worldwide trends in the prevalence of asthma symptoms: phase III of the International Study of Asthma and Allergies in Childhood (ISAAC). Thorax 2007; 62: 758-766.

45 Lai CK, Beasley R, Crane J, et al. Global variation in the prevalence and severity of asthma symptoms: phase three of the International Study of Asthma and Allergies in Childhood (ISAAC). Thorax 2009; 64: 476-483.

46 Asher MI, Keil U, Anderson HR, et al. International Study of Asthma and Allergies in Childhood (ISAAC): rationale and methods. Eur Respir J 1995; 8: 483-491.

47 International Union Against Tuberculosis and Lung Disease. The Global Asthma Report 2011. Paris, The International Union Against Tuberculosis and Lung Disease, 2011. www.globalasthmareport.org/2011/

48 Council of the European Union. Council conclusions on prevention, early diagnosis and treatment of chronic respiratory diseases in children. www.consilium.europa.eu/uedocs/cms_Data/docs/pressdata/en/lsa/126522.pdf Date last updated: December 1-2, 2011. Date last accessed: August 28, 2014

49 Samolinski B, Fronczak A, Kuna P, et al. Prevention and control of childhood asthma and allergy in the EU from the public health point of view: Polish Presidency of the European Union. Allergy 2012; 67: 726-731. 
50 Ring N, Pinnock H, Wilson C, et al. Understanding what asthma plans mean: a linguistic analysis of terminology used in published texts. Prim Care Respir J 2011; 20: 170-177.

51 The Center for Managing Chronic Disease. Asthma Health Outcomes Project. Asthma programs with an environmental component: a review of the field and lessons for success. Ann Arbor, Center for Managing Chronic Disease, 2007.

52 Erhola M, Mäkinen R, Koskela $\mathrm{K}$, et al. The asthma programme of Finland: an evaluation survey in primary health care. Int J Tuberc Lung Dis 2003; 7: 592-598.

53 Tuomisto L, Erhola M, Kaila M, et al. Asthma programme in Finland: high consensus between general practitioners and pulmonologists on the content of an asthma referral letter. Respir Med 2004; 13: 205-210.

54 Tuomisto LE, Erhola M, Luukkaala T, et al. Asthma programme in Finland: did the use of secondary care resources become more rational? Respir Med 2010; 104: 957-965.

55 Reissell E, Herse F, Väänänen J, et al. The price of asthma in Finland 1987-2005 - costs and financial benefits of treating a chronic disease. Finn Med J 2010; 65: 811-816.

56 Kauppi $\mathrm{P}$, Linna $\mathrm{M}$, Hämäläinen $\mathrm{P}$, et al. Hospital treatment and emergency visits for asthma as quality indicators. Finn Med J 2010; 65: 3497-3502.

57 Kainu A, Pallasaho P, Piirilä P, et al. Increase in prevalence of physician-diagnosed asthma in Helsinki during the Finnish Asthma Programme: improved recognition of asthma in primary care? A cross-sectional cohort study. Prim Care Respir J 2013; 22: 64-71.

58 Kauppi P, Linna M, Martikainen J, et al. Follow-up of the Finnish Asthma Programme 2000-2010: reduction of hospital burden needs risk group rethinking. Thorax 2013; 68: 292-293.

59 Jantunen J, Kauppi P, Linna M, et al. Asthma and allergy costs in Finland are high but decreasing. Finn Med J 2014; 69: 641-646.

60 Kauppi P, Peura S, Salimäki J, et al. Reduced severity and improved control of self-reported asthma in Finland during 2001-2010. Asia Pac Allergy 2015; 5: 32-39.

61 Barcala FJ, Viñas JA, Cuadrado LV, et al. Trends in hospital admissions due to asthma in north-west Spain from 1995 to 2007. Allergol Immunopathol 2010; 38: 254-258.

62 Pascal L, Fuhrman C, Durif L, et al. Trends in hospital admissions for asthma in France, 1998-2002. Rev Mal Respir 2007; 24: 581-590.

63 Bjerg A, Ekerljung L, Middelveld R, et al. Increased prevalence of symptoms of rhinitis but not of asthma between 1990 and 2008 in Swedish adults: comparisons of the ECRHS and GA ${ }^{2}$ LEN surveys. PLoS One 2011; 6: e16802.

64 Läkemedelsverket. Pharmacological treatment of asthma. Treatment recommendations (in Swedish). Date last updated: 2007. Date last accessed: June 12, 2015. https://lakemedelsverket.se/upload/halso-och-sjukvard/ behandlingsrekommendationer/astma2007_rek_bokm\%C3\%A4rken.pdf

65 Dansk Lungemedicinsk Selskab. Asthma: Treatment. Revision 2013. www.lungemedicin.dk/fagligt/39-astma-behandling/ file.html.

66 Norges Astma- og Allergiforbund. Facts about asthma 2006 (in Norwegian). Date last updated: June 12, 2014. Date last accessed: August 28, 2014. www.naaf.no/no/astma/fakta_om_astma/

67 Ekerljung L, Bjerg A, Bossios A, et al. Five-fold increase in use of inhaled corticosteroids over 18 years in the general adult population in West Sweden. Respir Med 2014; 108: 685-693.

68 Janson C, de Marco R, Accordini S, et al. Changes in the use of anti-asthmatic medication in an international cohort. Eur Respir J 2005; 26: 1047-1055.

69 EUROSTAT. European shortlist: cause of death statistics. http://epp.eurostat.ec.europa.eu/statistics_explained/index. php/Glossary:European_shortlist_of_causes_of_death Date last updated: April, 2014. Date last accessed: June 2, 2014.

70 Grol R, Grimshaw J. From best evidence to best practice: effective implementation of change in patients' care. Lancet 2003; 362: 1225-1230.

71 Fitzgerald JM, Quon B. The impact of asthma guidelines. Lancet 2010; 376: 751-753.

72 Lahdensuo A, Haahtela T, Herrala J, et al. Randomised comparison of self management and traditional treatment of asthma over one year. BMJ 1996; 312: 748-752.

73 Lahdensuo A, Haahtela T, Herrala J, et al. Randomised comparison of cost effectiveness of guided self management and traditional treatment of asthma in Finland. BMJ 1998; 316: 1138-1139.

74 Gibson PG, Powell H, Coughlan J, et al. Self-management education and regular practitioner review for adults with asthma. Cochrane Database Syst Rev 2003, 1: CD001117.

75 Mihaltan F, Nemes R, Ionescu A. Effectiveness of continuity in "World Day of COPD" awareness campaign on case finding for COPD in target populations. Eur Respir J 2011; 38: Suppl 55, s186.

76 Tan WC, Ait-Khaled N. Dissemination and implementation of guidelines for the treatment of asthma. Int J Tuberc Lung Dis 2006; 10: 710-716. 